() Entomologica Fennica. 12.X.1993

\title{
New species of Moritzoppia and Medioppia from the Beskidy Mountains, Poland (Acarina, Oribatida, Oppiidae)
}

\author{
Ritva Niemi \& Piotr Skubała
}

Niemi, R. \& Skubała, P. 1993: New species of Moritzoppia and Medioppia from the Beskidy Mountains, Poland (Acarina, Oribatida, Oppiidae). Entomol. Fennica 4:195-200.

Moritzoppia sharipovi sp. n. and Medioppia beskidyensis sp. n. are described from Poland. $M$. sharipovi is distinguished from other species by the rostrum, sensilli, the crista and the large size. M. beskidyensis differs from all other species by the tubercles in the posterior margin of the prodorsum, the form of the rostrum, the number of genital hairs and the fusiform sensilli. A new combination, Medioppia ordunensis (Iturrondobeitia \& Saloña, 1988) comb. n. is presented.

Ritva Niemi, Zoological Museum, University of Turku, FIN-20500 Turku, Finland

Piotr Skubała, University of Silesia, Department of Ecology, Bakowa 9, 40007 Katowice, Poland

\section{Introduction}

The genus Moritzoppia Subías \& Rodríguez (1987) seems to be distributed only in the Holarctic Region. Subías \& Balogh (1989) listed eight species and two subspecies, and later Colloff \& Seyd (1991) described $M$. oreia, while Gordeeva \& Grishina (1991) described ten new species and one subspecies as belonging to this genus. Most of the species of this genus have a round rostrum, however there are a few species with incisions, such as $M$. escotata Subías \& Rodríguez, 1986, M. longilamellata Subías \& Rodríguez, 1986 and $M$. minuta Gordeeva \& Grishina, 1991. In the present paper a new species is described belonging to the species group with a three-part rostrum.

Subías \& Balogh (1989) included twelve species in the genus Medioppia Subías \& Minguez,
1985. Adding $M$. templadoi Pérez-Iñigo, 1988, $M$. truncata Iturrondobeitia \& Saloña, 1988, M. centrodentata Gordeeva \& Niemi, 1990, M. minimedia Arillo \& Subías, 1990 and the species described here, $M$. beskidyensis sp. n. altogether comprise seventeen species.

\section{Methods}

In the description, chaetotaxic notation and other characters, we follow the terminology of Balogh (1972, 1983) and Mahunka \& Zombori (1985), also indicated in Figs. 1 and 3. The illustrations have been made with the aid of a camera lucida attached to a compound microscope and the photographs with the SEM (JEOL JSM-5200). 

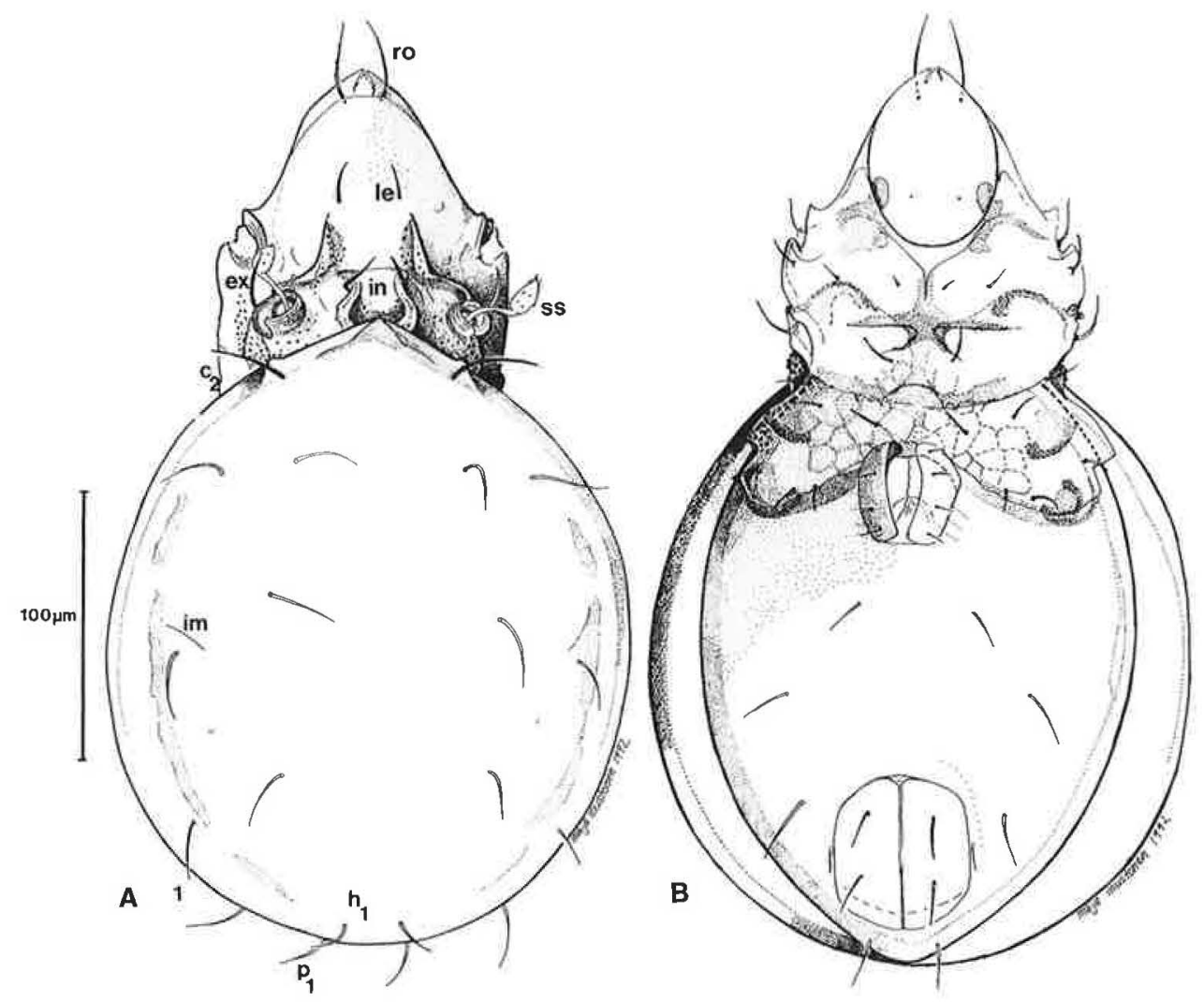

Fig.1. Morizoppia sharipovi sp. n. (holotype): dorsal (A) and ventral (B) side.

\section{Moritzoppia sharipovi sp. n.}

Figs. 1, 2

Type material. - Holotype: ९, Poland, Beskidy Mountains, (Pod Rysianka), $1080 \mathrm{~m}$ a.s.l. mixed forest (beech \& spruce) iii.84, P. Skubała, deposited in the Department of Ecology, University of Silesia, no.1. Paratypes: 3 ơ $^{7} \& 2$ OQ , same data as for holotype, deposited in the Zoological Museum, University of Turku, Finland, and 7 specimens (in beech forest - $1000 \mathrm{~m}$ a.s.1.), 26 specimens (mixed forest $1080 \mathrm{~m}$ a.s.l.) and 4 specimens (spruce forest $1170 \mathrm{~m}$ a.s.1.), deposited in the Department of Ecology, University of Silesia.

Diagnosis: Moritzoppia sharipovi can be distinguished from other species of this genus by the form of the rostrum, the shape of the sensilli, the crista and the large size. In addition to the combination of characters stated, it differs from following, other morphologically very similar species with a three-part rostrum by the costulae; the lamellae of $M$. longilamellata extend some distance anterior of the bases of setae $l e$ and those of $M$. minuta and $M$. escotata extend as far as the bases of setae le. Additionally the epimeral hairs, $4_{b}$ of $M$. longilamellata and $M$. escotata are at least twice the length of $4_{a}$ and $4_{c}$. The epimeral setae of the 4 series in $M$. sharipovi and $M$. minuta are subequal in length. $M$. sharipovi differs from $M$. escotata by the round form of the notogaster and the slit-like pori $\mathrm{im}$.

Description: Length 315-333 $\mu \mathrm{m}$ (6 ex.) (327 $\mu \mathrm{m}$ holotype), width 173-209 $\mu \mathrm{m}$ (6 ex.) $(197 \mu \mathrm{m}$ holotype). Colour light brown. 


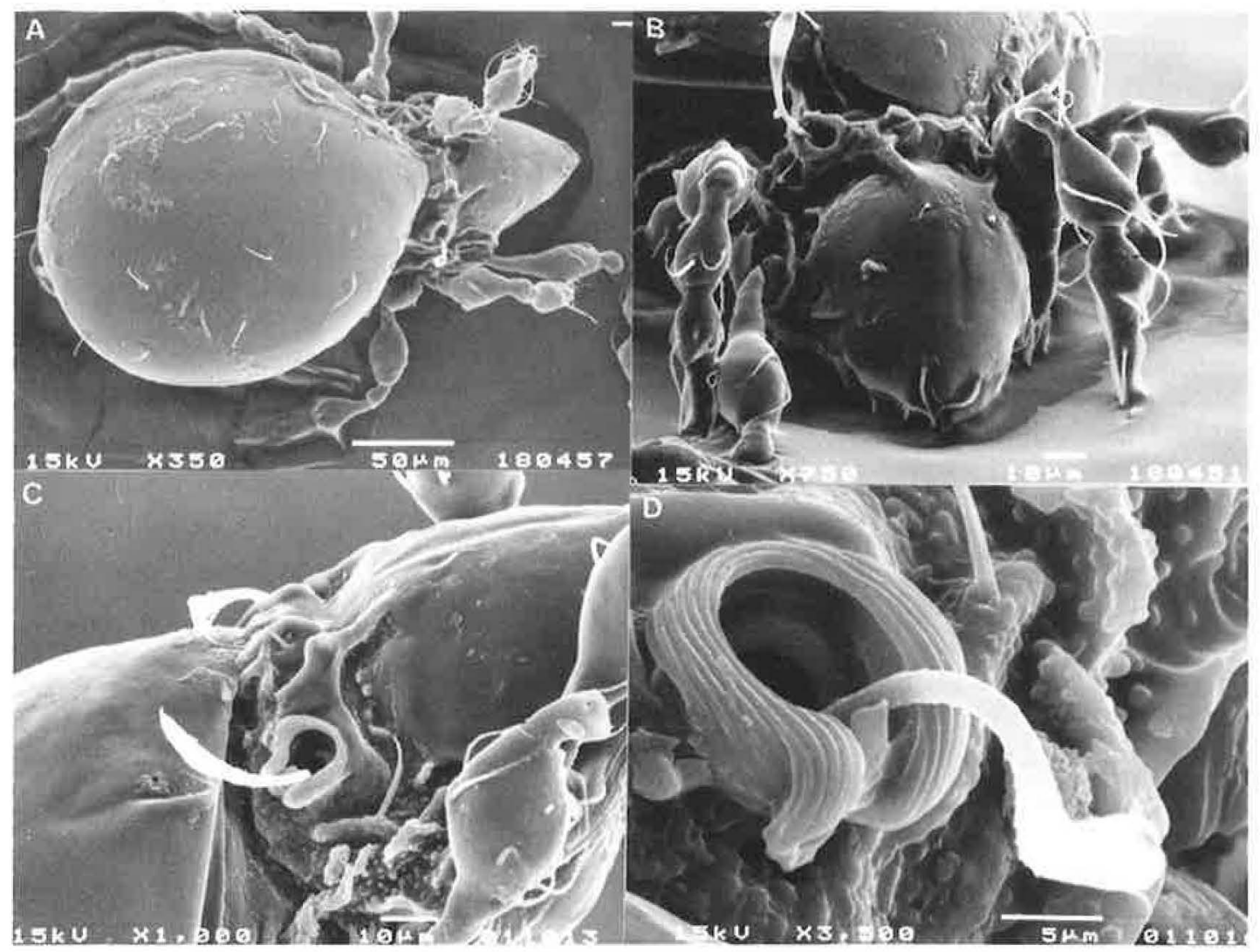

Fig. 2. Moritzoppia sharipovi sp. n. (paratype): A. dorsal side B. front of the prodorsum C. (other paratype) exobothridial region $\mathrm{D}$. bothridial region.

Prodorsum. Rostrum in three parts, the middle part shorter than the lateral ones (Figs. 1A, 2A, B). Rostral setae (ro) long and slightly serrate, reaching over the point of the rostrum. Lamellar setae (le) nearer to interlamellar setae than ro. Le short and smooth, situated some distance anterior to apices of the costulae on about the same level as tectopedia first. Interlamellar setae (in) long and smooth, situated outside lyre-shaped prodorsal ornamentation. The bothridium round (Fig. 2C, D). Sensilli (ss) fusiform, head with a few rows of minute hairs. Exobothridial hairs (ex) long and smooth. The relative lengths of setae: $r o>e x=$ in $>$ le.

Notogaster round; ten pairs of notogastral setae. All setae smooth and progressively shorter from setae $C_{2}$ to setae $p_{1}$. Distance between hairs $h_{l}$ smaller than the distance between hairs $p_{l}$. Pori im slit-like. Surface smooth. Crista small.
Ventral side. The surface of the epimeral plate $e p_{4}$ with polygonal reticulation. Epimeral setal formula 3-1-3-3 (Fig. 1B). All setae short and smooth. Setae $I_{c}$ on pedotecta 1 . Four pairs of genital hairs. Setae $a d_{3}$ in preanal position, $a d_{2}$ in adanal position and setae $a d_{l}$ in postanal position. All adanal setae simple. Pori iad in adanal position.

Etymology. We dedicate the new species to deceased oribatologist and friend Dr. Sarvar Sharipov, Uzbekistan, Tashkent.

\section{Medioppia beskidyensis sp. $\mathbf{n}$.}

Figs. 3-5

Type material. - Holotype: ф, Poland, Beskidy Mountains, (Pod Rysianka), $1080 \mathrm{~m}$ a.s.l. mixed forest (beech \& spruce), iii.84, P. Skubała, in the Department of 

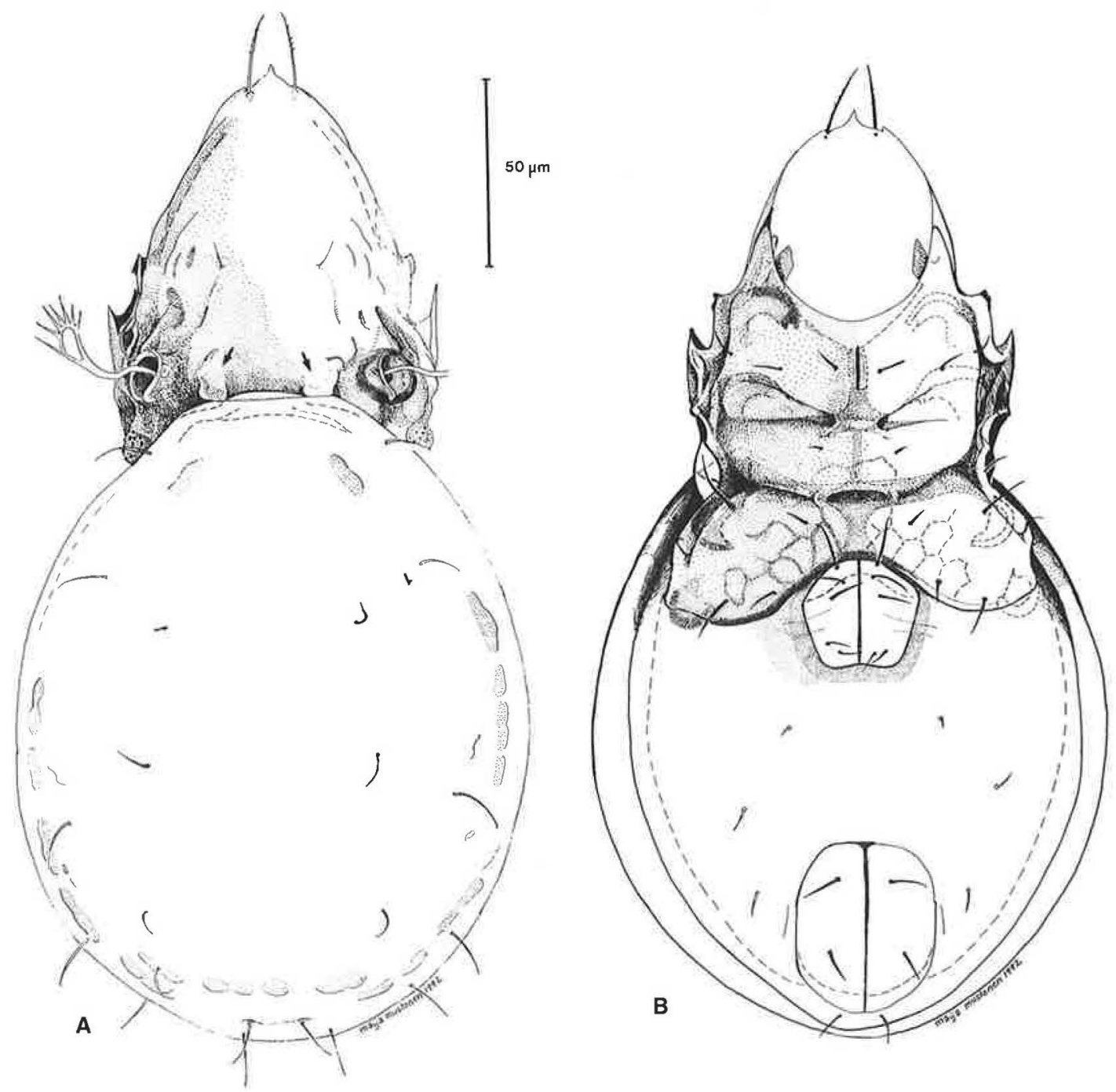

Fig.3. Medioppia beskidyensis sp. n. (holotype): dorsal (A) and ventral (B) side.

Ecology, University of Silesia, no. 2. Paratypes: $20^{7} 0^{7} \& 2$ QQ, with the same data, deposited in the Zoological Museum, University of Turku, Finland and 79 specimens (in beech forest $1000 \mathrm{~m}$ a.s.l.), 16 specimens (in mixed forest) and 68 specimens (in spruce forest) with same local data, deposited in the department of Ecology, University of Silesia, Poland.

Diagnosis: This new species has five pairs of genital setae like M. loksai (Schalk, 1966) and $M$. vera (Michelčič, 1956) but it differs from those and all other species by the tubercles at the basal part of the prodorsum, the form of the rostrum and the sensilli.
Description: Length 253-271 $\mu \mathrm{m}$ (5 ex.) (263 $\mu \mathrm{m}$ holotype), width 130-136 $\mu \mathrm{m}$ (5 ex.) $(136 \mu \mathrm{m}$ holotype). Colour light brown.

Prodorsum. Rostrum in three parts. The aciculate medial tooth considerably larger and longer than small distantly-spaced lateral teeth (Figs. 3A, 4A). Ro long and rough. Le and in short and smooth. Le situated nearer to in than ro. Lamellae barely visible. $S s$ fusiform with 7-8 hairs of a different size (Fig. 4D). Bothridium a horseshoe shaped (Fig. 4C). At the basal part of the prodorsum, two high tubercles (Figs. 3A, 


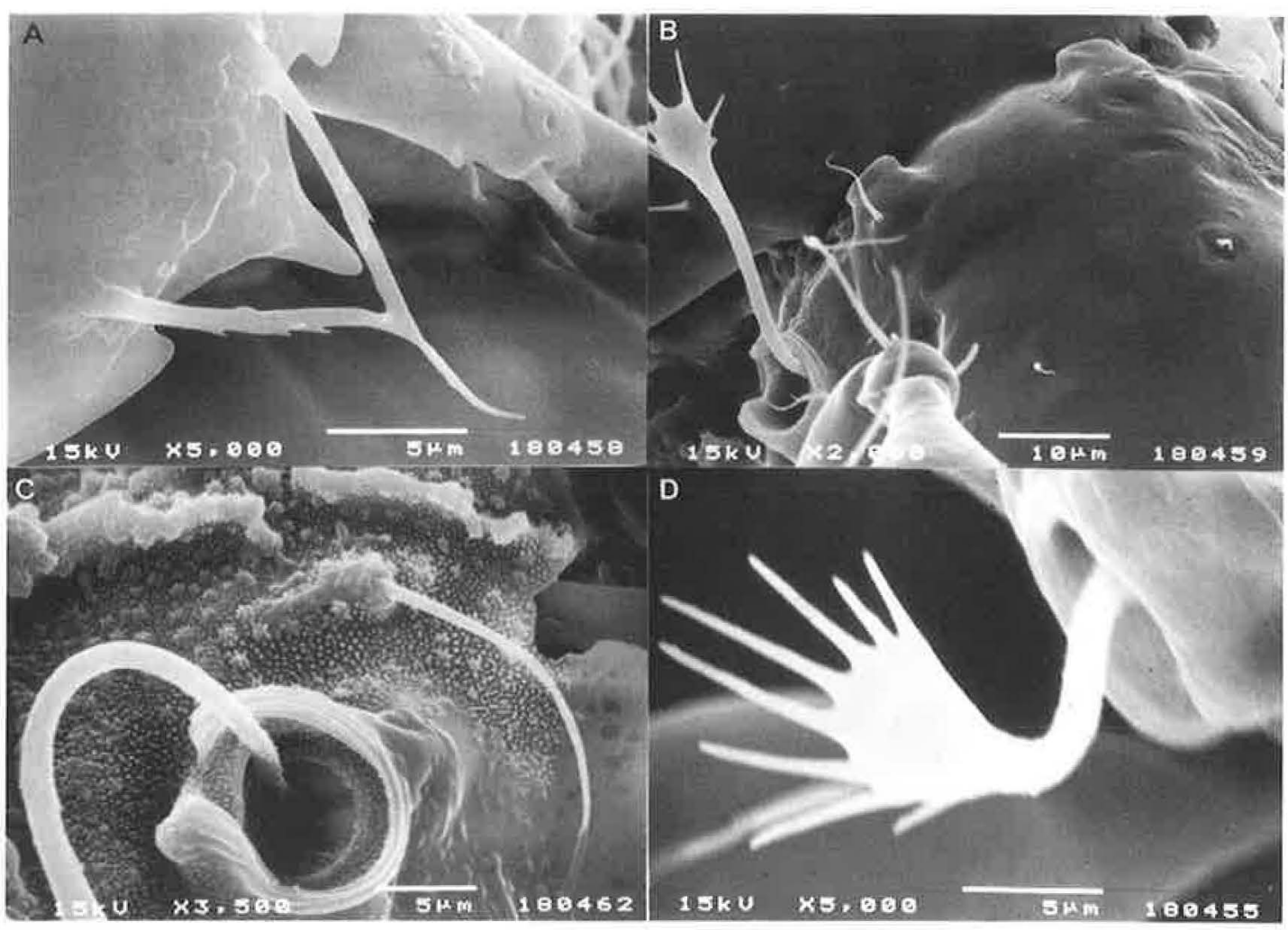

Fig. 4. Medioppia beskidyensis sp. n. (paratype): A. rostrum B. tubercles at the basal part C. the exobothridial region $\mathrm{D}$. sensillus

4B). Ex long and smooth. The relative lengths of setae: $r o>e x>l e=i n$. Surface of the exobothridial region granulated.

Notogaster generally oval, but with the anterior margin of the notogaster cut off (Figs. 3A, $5 \mathrm{~A}, \mathrm{~B})$. Crista present. Ten pairs of short, smooth setae.

Ventral side. The formula of the epimeral setae 3-1-3-3 (Figs. 3B, 5C, D). All setae simple. The apodemata; $a p o_{s j}$ and $a p o_{4}$ thicker than the other ones. Five pairs of genital setae, the first pair longer than the others. Setae $a d_{3}$ in preanal position, $a d_{2}$ in adanal position and setae $a d_{1}$ in postanal position. All adanal setae simple. Pori iad in adanal position.

Lauroppia ordunensis Iturrondobeitia \& Saloña, 1988 is a close relative of $M$. beskidyensis, with five pairs of genital hairs and the rostrum in three parts but is distinguished by longer interlamellar hairs and an "S" shaped form in the posterior margin of the prodorsum. Because of the above mentioned characters and absence of lamellar costulae we wish to include $L$. ordunensis in the genus Medioppia.

Acknowledgements. We wish to thank Dr. Elena Gordeeva for her comments on the new species, Dr. J. C. Iturrondobeitia and Dr. M. Saloña for the loan of the type material, Lauroppia ordunensis and we are very grateful to Dr. C. Pérez-Iñigo, Sr. for his friendly advice and the loan of the type material of Oppiella acutirostris Pérez-Iñigo, Jr. 1990 and Oppia vera Mihelčič, 1956. To Dr. L.S. Subías we send special thanks for his opinions relating to the closely related species of the here described ones, the loan of the type material, Moritziella escotata Subías et Rodríguez, 1986 and the critical reading of the manuscript. We are very grateful to Mrs. Alice Moore for her having checked the English texı. 


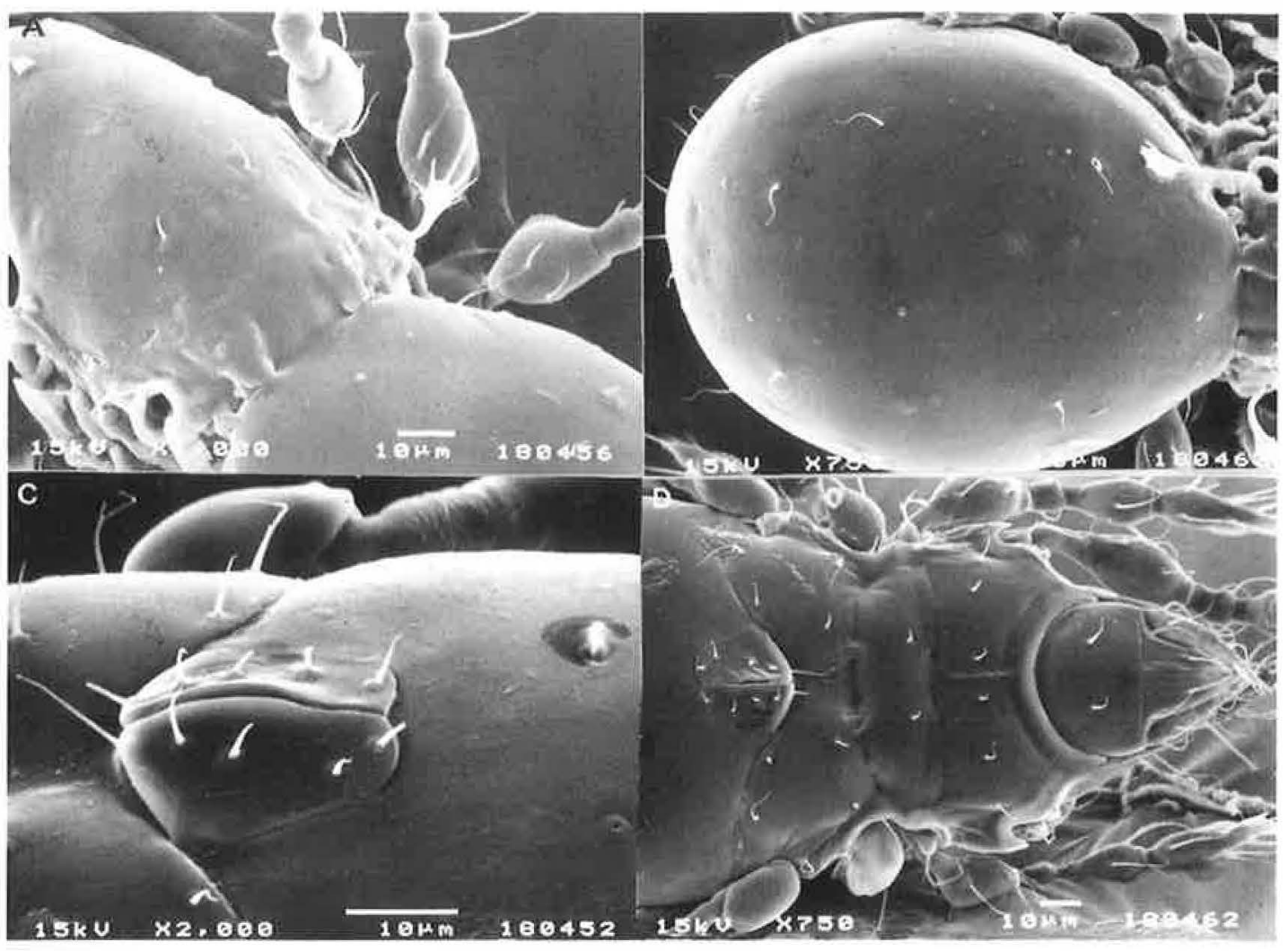

Fig. 5. Medioppia beskidyensis sp. n. (paratype): A. margin of the prodorsum with tubercles B. notogaster C. (other paratype) genital plate D. epimeral region.

\section{References}

Arillo, A. \& Subías, L. S. 1990: Tres nuevas especies de Oppiidae Grandjean, 1951 de Madeira (Acari, Oribatida). - Bol. Assoc. Esp. Entomol. 14:63-70.

Balogh, J. 1972: The Oribatids of the world. - Akadémiai Kiadó, Budapest, 188 pp., 71 pls.

-_ 1983: A partial revision of the Oppiidae Grandjean, 1954 (Acari: Oribatei). - Acat Zool. Acad. Sci. Hung. 29:1-79.

Colloff, M. J. \& Seyd, E. L. 1991: A new species of Moritzoppia from montane sites in the British Isles, with a redescription of M. clavigera (Hammer, 1952) (Acari: Oribatida: Oppiidae). — J. Nat. Hist. 25:1067-1074.

Gordeeva, E. \& Grishina, L. G. 1991: New species of mites belonging to Oppiidae (Sarcoptiformes, Oribatei) from Siberia. — Zool. Zh. 70:39-49.

Gordeeva, E. V. \& Niemi, R. 1990: Medioppia centrodentata sp. n. (Acarina, Oribatei, Oppiidae) from Bulgaria. - Entomol. Fennica 1:129-130.

Pérez-Iñigo, C. 1988: Catalogo de oribátidos (Acari,
Oribatei) de la Sietra de Guadarrama. - Graellsia 44:31-64.

Schalk, V. 1966: Zwei neue Oribatiden (Acarina) aus den Südkarpaten. - Deutsche Entomol. Zeit. (N.F.) 13:273-277.

Subías, L. S. \& Balogh, P. 1989: Identification keys to the genera of Oppiidae Grandjean, 1951 (Acari: Oribatei). - Acta Zool. Hung. 35:355-412.

Subías, L. S. \& Mínguez, M. 1985: Medioppiinae n. subfam. de oppidos (Acari, Oribatida, Oppiidae) y description de Medioppia tridentata n. gen. y n. sp. - Redia 68:61-67.

Subías, L. S. \& Rodríguez, P. 1986: Oppiidae (Acari, Oribatida) de los sabinares. - (Juniperus thurifera) de España VI. Neotrichoppia (Confinoppia) n. subg. y Moritziella Balogh, 1983. — Redia 69:115-130.

- 1987: Los opidos (Acari, Oribatida) de los sabinares albares espanoles VII. Hypogeoppia, Oppiella y Lauroppia. - Misc. Zool. 11:105-111.

Received 24.XI.1992 